\title{
Solute Carrier Family
}

National Cancer Institute

\section{Source}

National Cancer Institute. Solute Carrier Family. NCI Thesaurus. Code C117186.

A large group of integral membrane proteins that are involved in either facilitated or secondary active transport of solutes across cellular membranes. There are over 300 member proteins organized into approximately 50 families. The members of each family share both substrate preference and at least $20 \%$ amino acid sequence identity. 